\title{
Penyuluhan Pertanian Teknik Budidaya Bawang Merah Pada Ibu-Ibu Pembinaan Kesejahteraan Keluarga (Pkk) Desa Kalibeji
}

\author{
Suhartono $^{1}$, Aulia Rahma Faizati ${ }^{2}$, Kana Tania Wijaya ${ }^{3}$, Alivia Fanny \\ Fitriana $^{4}$, Amir Fiqri Gholidho ${ }^{5}$, Zharfan Afina ${ }^{6}$, Laeli Fuziyah Hasna ${ }^{7}$, \\ Lelya Gussyanti ${ }^{8}$, Sigit Santoso ${ }^{9}$, Nisarofa Istiqomah ${ }^{10}$, Dwinanda Wuri \\ Harsanti $^{11}$ \\ ${ }^{1}$ Pendidikan Guru Sekolah Dasar, Fakultas Keguruan dan Ilmu Pendidikan \\ 1,2,3,4,5,6,7,8,9,10,11 Universitas Sebelas Maret, Surakarta \\ suhartono@staff.uns.ac.id
}

\begin{abstract}
Agricultural extension activity in Kalibeji Village aims to increase the knowledge and understanding of mothers in fostering family welfare (PKK) in the development of shallow cultivation. This agricultural extension uses group extension methods and lecture and discussion extension techniques. This activity was able to increase the understanding of PKK mothers regarding the control and planting of shallots, increase awareness of the importance of environmental sustainability so that they choose to control pests in an environmentally friendly way, and increase the enthusiasm of PKK mothers in developing cultivation in Kalibeji Village in order to increase the productivity of shallots. The conclusions from agricultural extension activities on shallot cultivation techniques are (1) pheromone traps are an easy-to-use and environmentally friendly method of controlling shallot caterpillar pests. (2) one of the conditions for growing shallots is that it requires sunlight for approximately 12 hours and requires good groundwater conditions, namely groundwater in a state of field capacity or moist but not muddy.
\end{abstract}

Keywords: counseling; cultivation; KKN; shallots

\begin{abstract}
ABSTRAK
Kegiatan penyuluhan pertanian di Desa Kalibeji bertujuan untuk meningkatkan pengetahuan dan pemahaman ibu-ibu pembinaan kesejahteraan keluarga (PKK) dalam pengembangan budidaya bawang merah. Penyuluhan pertanian ini menggunakan metode penyuluhan kelompok dan teknik penyuluhan ceramah dan diskusi. Kegiatan ini mampu meningkatkan pemahaman ibu-ibu PKK terkait pengendalian dan penanaman bawang merah, meningkatkan kesadaran akan pentingnya kelestarian lingkungan sehingga memilih untuk mengendalikan hama dengan cara yang ramah lingkungan serta meningkatkan semangat ibu-ibu PKK dalam mengembangkan budidaya di Desa Kalibeji guna meningkatkan produktivitas bawang merah. Kesimpulan dari kegiatan


penyuluhan pertanian teknik budidaya bawang merah yaitu (1) Feromon perangkap merupakan cara pengendalian hama ulat bawang merah yang mudah digunakan dan ramah lingkungan. (2) Salah satu syarat tumbuh bawang merah yaitu membutuhkan penyinaran matahari kurang lebih 12 jam dan membutuhkan kondisi air tanah yang baik, yaitu air tanah dalam keadaan kapasitas lapang atau lembab tetapi tidak becek.

Kata kunci: bawang merah; budidaya; KKN; penyuluhan

\section{PENDAHULUAN}

Bawang merah merupakan tanaman holtikultura yang memiliki nilai ekonomi tinggi dan jenis tanaman yang menjadi bumbu berbagai masakan Asia Tenggara dan dunia. Peminat bawang merah terus mengalami peningkatan setiap tahunnya sejalan dengan peningkatan jumlah penduduk. Tetapi, produksi bawang merah saat ini belum optimal. Badan Pusat Statistik dalam Dewi dan I Ketut (2016) menyatakan bahwa permintaan bawang merah cenderung meningkat setiap saat, sementara produksi bawang merah bersifat musiman. Hal ini menyebabkan terjadinya luapan karena adanya ketidakseimbangan antara pasokan dan permintaan. Permintaan bawang merah juga terus meningkat sejalan dengan peningkatan jumlah penduduk dan kebutuhan konsumsi bawang merah masyarakat. Selain itu, menurut Suriani (2011), sebagai salah satu komoditas yang banyak diminati masyarakat, potensi pengembangan bawang merah masih terbuka lebar tidak hanya saja untuk kebutuhan dalam negeri tetapi juga luar negeri.

Melihat nilai ekonomi yang tinggi, masyarakat di Desa Kalibeji sedang mengembangkan pertanian bawang merah guna meningkatkan produksi bawang merah. Peningkatan minat masyarakat untuk membudidayakan bawang merah harus selalu digalakkan mengingat potensi bawang merah yang memiliki nilai ekonomi tinggi sehingga dapat menjadi sumber pendapatan masyarakat (Marlin et al, 2020). Pengembangan pertanian bawang merah dilakukan tidak hanya penanaman di area persawahan saja tetapi juga di pekarangan rumah yang dilakukan oleh ibu-ibu pembinaan kesejahteraan keluarga (PKK) dengan menggunakan polybag. 
Minat masyarakat Desa Kalibeji untuk menanam bawang merah sudah cukup tinggi. Akan tetapi, teknik budidaya bawang merah belum sepenuhnya dikuasai. Teknik budidaya bawang merah yang menjadi masalah yaitu dalam penanganan hama dan penyakit bawang merah menggunakan cara yang lebih ramah lingkungan. Masyarakat Desa Kalibeji kebanyakan masih menggunakan pestisida. Penggunaan pestisida secara terus menerus dan dalam jangka waktu panjang dapat mencemari lingkungan baik air, tanah maupun udara. Menurut Khairia (2009), penggunaan pestisida bertujuan untuk menekan populasi Organisme Pengganggu Tanaman (OPT) secara cepat dibandingkan dengan pengendalian lainnya, karena keunggulan pestisida tersebut. Akibat dari penggunakaan pestisida secara terus menerus dapat menimbulkan pencemaran terhadap lingkungan baik lingkungan perairan, tanah, udara naupun makhluk hidup yang bukan sasaran.

Adanya hama dan penyakit tentu saja menjadi ancaman yang serius bagi petani karena dapat menyebakan menurunnya hasil panen bahkan bias gagal panen. Masalah utama yang dihadapi petani yaitu hama ulat dan penyakit layu. Hama ini merupakan hama utama di sentra produksi bawang merah. Kehilangan hasil panen akibat serangan ulat bawang dapat mencapai 100\% jika tidak dilakukan upaya pengendalian karena hama ini bersifat polifag (Moekasan dan Basuki, 2007). Pengendalian hama dan penyakit sangat penting diberikan kepada peani sehingga petani dapat melakukan pengendalian hama dan penyakit bawang merah.

Tujuan dari penyuluhan pertanian ini adalah untuk memberikan pengetahuan tentang budidaya bawang merah guna meningkatkan hasil panen petani mulai dari syarat tumbuh bawang merah, pengolahan tanah, penanaman, perawatan, pengendalian hama dan penyakit, panen serta pasca panen. Akan tetapi lebih menekankan pada pengendalian hama dan penyakit tanaman bawang merah. Manfaat bagi petani dengan adanya penyuluhan pertanian ini adalah petani dapat mengambil dan menerapakan materi yang diberikan sehingga dapat mengatasi permasalahan yang terjadi pada usahatani bawang merah dan dapat meningkatkan hasil panen. 


\section{TINJAUAN PUSTAKA}

\section{Bawang Merah}

Bawang merah (Allium ascalonicum L.) merupakan salah satu umbiumbian yang banyak dimanfaatkan sebagai bumbu dapur. Sesuai dengan namanya bawang ini memiliki warna merah keunguan. Berdasarkan penelitian Karo dan Manik (2020), keragaman karakter warna umbi beberapa varietas menunjukkan bahwa keragaman warna umbi setiap varietas berbeda. Keragaman warna dan bentuk umbi bawang merah yang dihasilkan dapat mempengaruhi ketertarikkan konsumen. Keragaman umbi bawang merah yang disukai oleh konsumen yaitu berwarna merah, umbinya padat dan besar, rasanya pedas dan aromanya wangi.

Salah satu varietas bawang merah yang terkenal yaitu Bima Brebes. Bawang merah varietas Bima Brebes dilepas tahun 1984, telah didiseminasikan di Brebes sejak 1985. Berdasarkan hasil survey alasan yang dikemukakan petani mengapa menanam varietas Bima Brebes adalah hasilnya tinggi $=+10$ ton/ha, umur panen genjah = 55-60 HST, tahan ditanam dimusim hujan, ukuran umbi sedang-besar, warna umbi merah muda-merah tua, dan disukai pasar (Basuki et al, 2017).

\section{Budidaya}

Keterbatasan lahan di era globalisasi ini tidak menutup kemungkinan untuk melakukan budidaya bawang merah. Penggunaan polybag sebagai wadah media tanam menjadi alternatif dalam budidaya bawang merah. Budidaya dalam polybag menggunakan media tanam berupa campuran tanah, sekam padi, dan kompos dengan perbandingan (1:1:2). Untuk pemeliharaan yang perlu dilakukan antara lain penyiraman, pemupukan, penyiangan, dan pengendalian OPT.

Salah satu penunjang keberhasilan dalam budidaya bawang merah yaitu penggunaan benih bermutu. Ciri-ciri benih bawang merah yang bermutu yaitu tidak terkena penyakit, tidak berjamur, dan tidak kopong (kosong). Benih bawang merah didapatkan dari bawang merah yang sudah dipanen lalu dikeringkan. Pengeringan benih bawang merah dilakukan di rumah pengeringan dengan jangka 
waktu tiga hingga empat minggu. Setelah itu dipindahkan ke lantai kering dengan jangka waktu satu minggu, lalu diseleksi menjadi benih (Onibala et al, 2019).

Tanaman bawang merah memerlukan pengairan setiap pagi dan sore hari. Pada musim kemarau, penyiraman dapat di lakukan sebanyak dua kali. Selain pagi dan sore penyiraman juga dilakukan saat setelah hujan turun untuk membasuh percikan air hujan yang menempel pada daun, tujuannya untuk menghilangkan embun tepung pada daun dan mengurangi resiko serangan penyakit tular tanah dan fusarium. Setelah tanaman berumur dua bulan, penyiraman harus di kurangi, agar diperoleh umbi yang berwarna merah cerah (Rahmadiah et al, 2021).

\section{Penyuluhan}

Hakekat penyuluhan adalah pendidikan non formal dalam mengubah perilaku sasaran baik dalam aspek kognitif, afektif, maupun psikomotor ke arah yang lebih baik sesuai dengan potensi dan kebutuhan. Penyuluhan harus mampu menciptakan kondisi masyarakat yang aktif dan berdaya dalam meningkatkan kualitas kehidupan. Oleh karena itu, penyuluh harus meningkatkan kemampuannya dalam mencari informasi inovasi melalui berbagai sumber informasi, memahami inovasi yang dibutuhkan petani, serta mengkomunikasikannya dengan bahasa yang mudah dipahami dan dilakukan secara dialogis (Anwas, 2011).

\section{METODOLOGI PENELITIAN}

Kegiatan penyuluhan pertanian ini dilakukan dengan pengenalan teknik budidaya bawang merah. Metode penyuluhan pertanian yang digunakan adalah metode kelompok, karena metode ini efisien digunakan jika jumlah sasaran yang banyak (Ningsih et al, 2019). Sedangkan teknik penyuluhan pertanian menggunakan teknik ceramah dan diskusi. Teknik ceramah dan diskusi ini dipilih dengan tujuan supaya sasaran dapat memahami materi dengan baik.

Kegiatan pengenalan teknik budidaya bawang merah dilakukan dengan cara memberikan materi dan mengikutsertakan para peserta secara aktif. Pemberian 
materi dilakukan dengan cara menampilkan materi pada power point dan mempresentasikan materi tersebut. Sasaran kegiatan yaitu ibu-ibu pembinaan kesejahteraan keluarga Desa Kalibeji. Setelah mengikuti kegiatan, sasaran kegiatan diharapkan dapat menjadi bekal pengetahuan dan menerapkan materi yang diberikan guna pengembangan budidaya bawang merah dan meningkatkan hasil produksi bawang merah.

\section{HASIL DAN PEMBAHASAN}

KKN kelompok 99 melaksanakan program kerja penyuluhan pertanian yang dilaksanakan pada tanggal 22 Agustus 2021. Penyuluhan pertanian dapat dikatakan sebagai ilmu sosial yang mempelajari sistem serta proses perubahan yang terjadi pada individu dan masyarakat supaya terwujud perubahan yang jauh lebih baik dalam bidang pertanian. Menurut Departemen Pertanian (2006), penyuluhan pertanian adalah suatu usaha atau upaya untuk mengubah perilaku petani dan keluarganya, agar mereka mengetahui dan mempunyai kemauan serta mampu memecahkan masalahnya sendiri dalam usaha atau kegiatan-kegiatan meningkatkan hasil usahanya dan tingkat kehidupannya. Penyuluhan pertanian adalah suatu cara atau usaha pendidikan yang bersifat di luar bangku sekolah (non-formal) untuk para petani dan keluarganya di pedesaan. Dalam penyuluhan terkandung arti aktivitas pendidikan di luar bangku sekolah (non-formal).

Penyuluhan ini menggunakan metode penyuluhan kelompok, karena karena metode ini efisien digunakan jika jumlah sasaran yang banyak. Selain itu, medote kelompok lebih menghemat waktu, tenaga dan biaya yang dikeluarkan. Metode kelompok dilakukan dengan cara penyuluh mendatangi tempat dimana kelompok tani berada. Tempat dilakukannya penyuluhan bisa di tempat salah satu warga maupun ditempat lainnya. Metode kelompok mudah efektif pula dilakukan karena nantinya penyuluh dapat memantau secara langsung pada sasaran penyuluhan yakni para petani. Sejalan dengan pendapat Kartasaputra dalam Setiana (2005) metode penyuluhan kelompok cukup efektif, dikarenakan petani dibimbing dan diarahkan secara kelompok untuk melakukan sesuatu kegiatan yang lebih produktif atas dasar kerja sama. Selain itu, Metode ini lebih 
menguntungkan karena memungkinkan adanya umpan balik, dan interaksi kelompok yang memberi kesempatan bertukar pengalaman maupun pengaruh terhadap perilaku dan norma para anggotanya.

Materi yang diberikan terkait dengan pengendalian hama ulat secara manual yaitu dengan menggunakan feromon perangkap. Feromon ini lebih mudah digunakan dan ramah lingkungan. Hal ini sesuai dengan penelitian Permana dan Rostaman (2006) yang menyatakan bahawa penggunaan feromon dianggap lebih mudah dilakukan dan aman bagi pemakai serta aman bagi lingkungan. Dampaknya dari penyampaian materi ini terhadap ibu ibu PKK adalah mereka tertarik untuk menggunakan feromon perangkat ini, karena dianggap mudah dan praktis serta ramah lingkungan dibandingkan harus menggunakan insektisida yang tidak ramah lingkungan jika digunakan dalam jangka panjang.

Permasalahan lain yang dihadapi ibu-ibu PKK adalah jika mereka menanam bawang merah di polybag biasanya busuk. Hal ini bisa disebabkan karena penanaman bawang merah ditidak memenuhi syarat tumbuh bawang merah yaitu kurangnya penyinaran matahari, karena bawang merah memerlukan penyinaran kurang lebih 12 jam sehari. Sesuai dengan pendapat Nazaruddin (1999) tanaman bawang merah ini membutuhkan penyinaran cahaya matahari yang maksimal (minimal $70 \%$ penyinaran) dengan suhu udaha $25-32^{\circ} \mathrm{C}$ dan kelembaban 50-70\%. Serta pendapat dari Rismunandar (1986) yaitu bawang merah akan membentuk umbi lebih besar bilamana ditanam di daerah dengan penyinaran lebih dari 12 jam.

Selain itu busuknya bawang merah bisa disebabkan karena terlalu banyak air pada saat penyiraman. Menurut Gultom dan Siska (2017), tanaman bawang merah membutuhkan kondisi air tanah yang baik, yaitu air tanah dalam keadaan kapasitas lapang atau lembab tetapi tidak becek sejak tumbuh hingga perkembangan umbi, karena jika kekeringan akan pada saat pertumbuhan vegetatif akan menghambat pertumbuhan sedangkan jika tanah becek atau terlalu banyak air akan memudahkan terjangkitnya penyakit busuk umbi.

Dengan adanya penyuluhan ini dapat meningkatkan pemahaman ibu-ibu PKK akan teknik budidaya bawang merah dan meningkatkan semangat ibu-ibu PKK untuk mengembangkan budidaya bawang merah di Desa Kalibeji. Sehingga 
diharapkan dapat meningkatkan produktifitas bawang merah dan dapat memenuhi kebutuhan bawang merah.

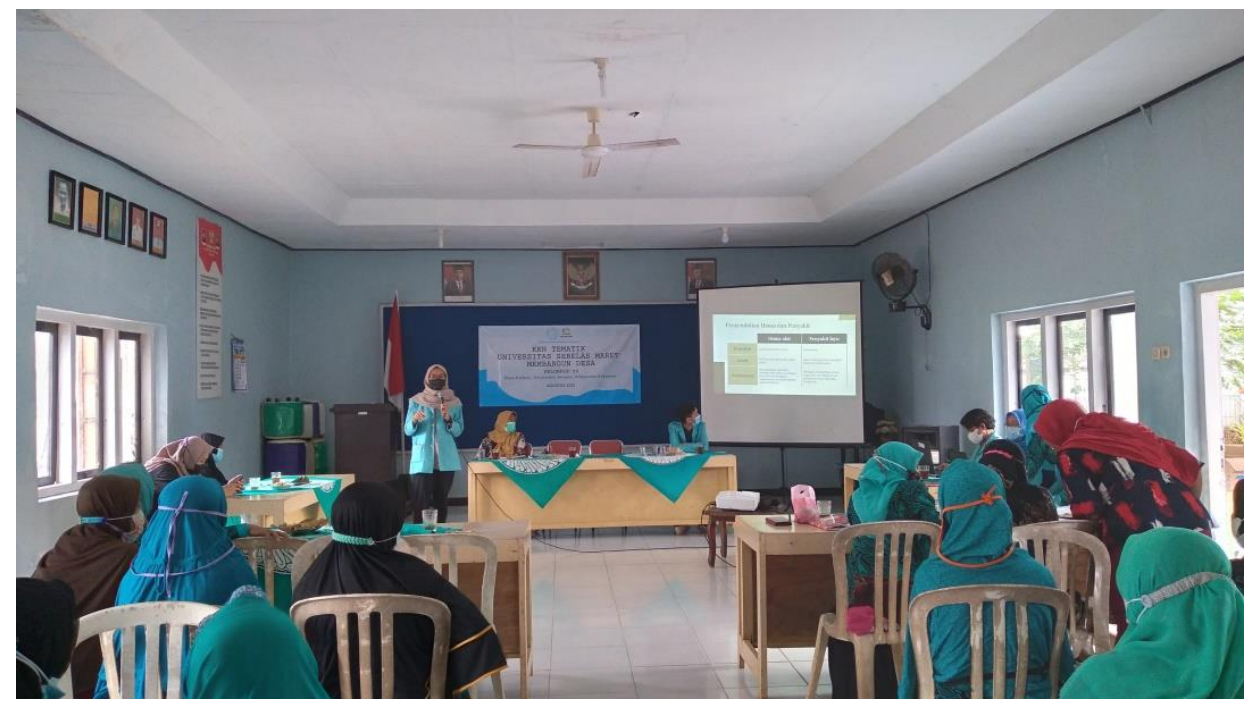

Gambar 1. Pelaksanaan Penyuluhan Pertanian

\section{KESIMPULAN}

Kesimpulan dari kegiatan penyuluhan pertanian yang telah dilaksanakan yaitu:

1. Program kerja penyuluhan pertanian teknik budidaya bawang merah dilakukan untuk memberikan pemahaman terkait budidaya bawang merah kepada ibu-ibu PKK Desa Kalibeji, dimana Desa Kalibeji sedang mengembangkan pertanian bawang merah.

2. Feromon perangkap merupakan cara pengendalian hama ulat bawang merah yang mudah digunakan dan ramah lingkungan.

3. Salah satu syarat tumbuh bawang merah yaitu membutuhkan penyinaran matahari kurang lebih 12 jam dan membutuhkan kondisi air tanah yang baik, yaitu air tanah dalam keadaan kapasitas lapang atau lembab tetapi tidak becek.

Program kerja penyuluhan pertanian ini mampu meningkatkan meningkatkan kesadaran akan pentingnya kelestarian lingkungan sehingga memilih untuk mengendalikan hama dengan cara yang ramah lingkungan serta 
meningkatkan semangat ibu-ibu PKK dalam mengembangkan budidaya di Desa Kalibeji guna meningkatkan produktivitas bawang merah.

\section{ACKNOWLEDGMENT}

Semua program kerja dari kelompok KKN UNS 99 ini dapat berjalan dengan baik berkat bantuan dari berbagai pihak, untuk itu kami mengucapkan terimakasih kepada:

1. UPKKN LPPM Universitas Sebelas Maret (UNS) yang telah memfasilitasi pelaksanaan kegiatan KKN periode Juli-Agustus 2021.

2. Kepala Desa Kalibeji dan seluruh masyarakat Desa Kalibeji yang sudah bersedia memberikan tempat dan kesempatan bagi kelompok KKN 99 untuk melaksanakan kegiatan hingga selesai.

\section{DAFTAR PUSTAKA}

Anwas, O.M. (2011). Kompetensi penyuluh pertanian dalam memberdayakan petani. Jurnal Matematika, Saint dan Teknologi Vol 12(1): 46-55.

Basuki, R.S., Khaririyatun, N., Sembiring, A., Arsanti, I.W. (2017). Studi adopsi bawang merah bima brebes dari balitsa di kabupaten brebes. Jurnal Horticultura Vol 27(2): 261-268.

Departemen Pertanian, (2006). Undang-Undang Republik Indonesia Nomor 16 Tahun 2006 Tentang Sistem Penyuluhan Pertanian, Perikanan dan Kehutanan. Jakarta.

Dewi, Mayun Karina dan I Ketut Sutrisna. (2016). Pengaruh tingkat produksi, harga, dan konsumsi terhadap impor bawang merah di Indonesia. Jurnal Ekonomi Pembangunan Universitas Udayana. Vol 5(1): 117-137.

Gultom, T. dan Siska, Panjaitan. (2017). Pengaruh Frekuensi Penyiraman Terhadap Pertumbuhan dan Produksi Tiga Varietas Bawang Merah (Allium cepa var. ascalonicum L). Jurnal Visi. Vol 25(1): 2955-2965.

Karo, B.B., dan Manik, F. (2020). Observasi dan adaptasi 10 varietas bawang merah (Allium cepa) di berastagi dataran tinggi basah. Jurnal Agroteknosains Vol 4(2).

Khairia, Wita. (2009). Dampak Penggunaan Pestisida Terhadap Keanekaragaman Arthropoda Tanah dan Kadar residu Pestisida Pada Buah Jeruk (Kasus Petani Holtikultura di Kabupaten Karo). Tesis. Medan: Sekolah Pascasarjana Universitas Sumatera Utara. 
Marlin, M., Sitorus, A., Solihin, M., Romeida, A., dan Herawati, R. (2020). Pemberdayaan Masyarakat Pesantren Ar-Rahmah Rejang lebong dalam Memanfaatkan Lahan Pekarangan dengan Budidaya Bawang Merah. Jurnal Agrokreatif. Vol 6(1): 53-61.

Moekasan, T.K., dan Basuki, R.S. (2007). Status Resistensi Spodoptera exigua pada Tanaman Bawang Merah Asal kabupaten Cirebon, Brebes, dan Tegal Terhadap Insektisida yang Umum Digunakan Petani di Daerah Tersebut. Jurnal Hortikultura. Vol 17(4): 21-24.

Nazaruddin. (1999). Budidaya dan Pengaturan Panen Sayuran Dataran Rendah. Jakarta: Penebar Swadaya.

Ningsih, Novia., La Nalefo., dan Ima Astuty Wunawarsih. (2019). Efektivitas merode kelompok terhadap peningkatan pengetahuan wanita tani dalam pemanfaatan lahan pekarangan di Desa Kalimas Kecamatan Kaledupa Kabupaten Wakatobi. Jurnal Ilmiah Membangun Desa dan Pertanian. Vol 4(2): 52-57.

Onibala, A.C., Pakasi, C.B.D., Ruauw, E. (2019). Analisa kelayakan finansial usaha penangkaran benih bawang merah di desa tonsewer selatan kecamatan tompaso barat kabupaten minahasa. AGRIRUD Vol 1(3): 265270.

Permana, Agus D. \& Rostaman. (2006). Pengaruh Jenis Perangkap dan Feromon Seks Terhadap Tangkapan Ngengat Jantan Spodoptera exigua. Jurnal HPT Tropika. Vol 6(1): 9-13.

Rahmadiah, Adiningsih, A.R., Sahrir, M., Naim, M.H., Sapan, A. (2021). Budidaya tanaman bawang merah dalam polybag menggunakan pupuk kompos di smk karya teknik watansoppeng. Jurnal Lepa-lepa Open Vol 1(3): 422-428.

Rismunandar. (1986). Membudidayakan Lima Jenis Bawang. Bandung : Sinar Baru.

Setiana, L. (2005). Teknik Penyuluhan dan Pemberdayaan Masyarakat. Yogyakarta: Penerbit ANDI.

Suriani, N. (2011). Bawang Bawa Untung, Budidaya Bawang Merah. Yogyakarta: Cahaya Atma Pustaka. 